Bangladesh J. Bot. 49(4): 997-1002, 2020 (December)

\title{
EFFECTS OF DROUGHT STRESS ON PIGMENT AND PROTEIN CONTENTS AND ANTIOXIDANT ENZYME ACTIVITIES IN FIVE VARIETIES OF RICE (ORYZA SATIVA L.)
}

\author{
Shukanta Saha*, Hasna Hena Begum, Shamima Nasrin and Rifat Samad ${ }^{1}$ \\ Department of Botany, Jagannath University, Dhaka-1100, Bangladesh
}

Key words: Drought stress, Pigment, Protein, Antioxidant enzyme activities, Rice

\begin{abstract}
Drought stress caused the decrease of pigment contents - chlorophyll a, chlorophyll b, chlorophyll a/b ratio, total chlorophyll content and carotenoids content of leaves of five rice varieties (var. BRRI Dhan-30, BRRI Dhan-32, BRRI Dhan-34, BRRI Dhan-38 and BRRI Dhan-56). Among five rice varieties, BRRI Dhan56 showed the least decrease of pigment content under stress. It caused the decrease of protein content of leaves of five rice varieties whereas BRRI Dhan-56 showed the least decrease $(3.64 \%)$ of protein content under stress. On the other hand, drought stress increased CAT and SOD activities in the leaf of five varieties of rice and BRRI Dhan-56 showed the highest increase of CAT (37.67\%) and SOD (94.17\%) activity under stress. It may be assumed that higher antioxidant enzymes activities (CAT and SOD) and less reduction of protein content were related to the mechanisms of drought tolerance in rice. It is indicated that BRRI Dhan56 may be drought tolerant while BRRI Dhan-30, BRRI Dhan-32, BRRI Dhan-34 and BRRI Dhan-38 were drought sensitive rice varieties. Drought tolerant rice variety is selected based on pigment content, protein content and antioxidant enzymes activities (CAT and SOD).
\end{abstract}

\section{Introduction}

Drought is one of the major abiotic stresses that severely affect and reduce the yield and productivity of food crops worldwide up to 70\% (Kaur et al. 2008, Thakur et al. 2010 and Akram et al. 2013). Drought is one of the main problems for many countries, and the severity of such issue increases when it comes as obstacle to ensure an optimum agricultural production for a country like Bangladesh (Habiba et al. 2012).

Rice (Oryza sativa L.) is one of the most widely consumed cereal crops, providing a staple diet for almost half of the world's population (Song et al. 2003). More than $90 \%$ of the world's rice is grown and consumed in Asia, where rice is cultivated on 135 million ha with an annual production of 516 million tones (Roy and Misra 2002). The predominant rice-growing areas in these regions are often threatened by severe drought stressed condition. Rice is most susceptible to drought stress. The response of plants to drought stress is complex and involves changes in their morphology, physiology and metabolism. Reduction of plant growth is the most typical symptom of drought stress (Sairam and Srivastava 2001). It inhibits the photosynthesis of plants, causes changes in chlorophyll contents and components and damage to the photosynthetic apparatus (Nayyar and Gupta 2006). A decrease in the protein concentration would be a typical symptom of oxidative stress and has frequently been observed in drought stressed plants (Seel et al. 1992, Moran et al. 1994). The induction of antioxidant enzyme activities is a general adaptation strategy which plants use to overcome oxidative stresses (Foyer and Noctor 2003).

Attempt was made to study the effect of drought stress on photosynthetic pigment content, protein content and antioxidant enzyme activities (CAT and SOD) of five varieties of rice and to characterize whether they are drought resistant or drought susceptible.

*Author for correspondence: <sahashukanta@gmail.com>. ${ }^{1}$ Department of Botany, University of Dhaka, Dhaka-1000, Bangladesh. 


\section{Materials and Methods}

A pot experiment was carried out at the research garden of the Department of Botany, Jagannath University, Dhaka. Seeds of BRRI Dhan-30, BRRI Dhan-32, BRRI Dhan-34, BRRI Dhan-38 and BRRI Dhan-56 were collected from Bangladesh Rice Research Institute (BRRI), Gazipur. Mixture of half loamy soil and half compost was used. The pot experiment was set up in net house of the research garden of Department of Botany, Jagannath University, Dhaka.

The seeds of five rice varieties were surface sterilized by agitation in $95 \%$ ethanol for $1 \mathrm{~min}$, followed by five washings with sterile water. Seeds were rinsed in distilled water for about $30 \mathrm{~min}$ and then were allowed to germinate on a filter paper in Petri dishes, moistened with $4 \mathrm{ml}$ of distilled water. The Petri dishes were arranged randomly and stored at room temperature ( $24 \pm 2$ ${ }^{\circ} \mathrm{C}$ ) under dark conditions. The Petri dishes were covered to prevent the loss of moisture by evaporation under laboratory condition. The germination of seeds were observed carefully and within three days the seeds were germinated and the germinated 8 seeds were sown in each pots. Drought stress was imposed by withholding irrigation at 21 days after sowing in 25 pots. Water level in well-watered treatment (control) was maintained at $5 \mathrm{~cm}$ above the surface of the soil in the rest 25 pots. The experiment was arranged with completely randomized design (CRD) with five replications.

Pigment contents were analysed at 11 days of treatment. Chlorophyll a and $b$, total chlorophyll content, chlorophyll $\mathrm{a} / \mathrm{b}$ ratio and carotenoid contents of leaves were determined for each treatment. The amount of chlorophyll $\mathrm{a}$ and $\mathrm{b}$ was determined by using specific absorption coefficient of Mackinney (1940) and the formulae of Maclachlan and Zalik (1963). Total chlorophyll content was estimated by using the equation of Hiscox and Israelstam (1979). The amount of carotenoid was determined by the equation of Von Wettstein (1957). Protein content of leaves for each treatment was determined at 15 days after stress by the method of Lowry et al. (1951). The method of Zhang et al. (2005) was employed to determine the catalase (CAT) activity and superoxide dismutase (SOD) activity of leaf for each treatment at 15 days after stress.

\section{Results and Discussion}

The pigment content of leaves were analysed at 11 days of treatment (Fig. 1a, b, c, d, e). Drought stress decreased chlorophyll a content in the leaves of BRRI Dhan-30, BRRI Dhan-32, BRRI Dhan-34, BRRI Dhan-38 and BRRI Dhan-56 by 45, 40.21, 21.47, 14.38 and 7.45\%, respectively. Among the rice varieties, BRRI Dhan-56 showed the least decrease of chlorophyll a content under stress (Fig. 1a). Drought stress decreased chlorophyll b content in BRRI Dhan-30, BRRI Dhan-32, BRRI Dhan-34, BRRI Dhan-38 and BRRI Dhan-56 by 29.8, 29.9, 17.19, 17.46 and $8.97 \%$, respectively where BRRI Dhan-56 showed the least decrease of chlorophyll b content under stress (Fig. 1b). It decreased chlorophyll a/b ratio by 34.67, 29.21, 28.64, 19.42 and 6.55\% in BRRI Dhan-30, BRRI Dhan-32, BRRI Dhan-34, BRRI Dhan-38 and BRRI Dhan-56, respectively. Among the rice varieties, BRRI Dhan-56 showed the least decrease of chlorophyll $\mathrm{a} / \mathrm{b}$ ratio under stress (Fig. 1c). Drought stress decreased total chlorophyll content by 46.4, 45.83, 43.14, 38.25 and $21.31 \%$ in BRRI Dhan-30, BRRI Dhan-32, BRRI Dhan-34, BRRI Dhan-38 and BRRI Dhan-56, respectively and BRRI Dhan-56 showed the least decrease of total chlorophyll content under stress (Fig. 1d) and carotenoid content decreased by 25.64, 19.04, 16.64, 15.03 and 14.09\% in BRRI Dhan-30, BRRI Dhan-32, BRRI Dhan-34, BRRI Dhan-38 and BRRI Dhan-56, respectively (Fig. 1e). The results are in agreement with Nasrin et al. (2020) who described a significant decrease of chlorophyll a and $b$, total chlorophyll and carotenoid content in rice var. BRRI Dhan-24. Similarly, Drought stress decreased chlorophyll content in raddish (Akram et al. 
2016). The decrease of chlorophyll content may slow down the rate of photosynthesis (Saha et al. 2016). These results indicated that among five varieties, only BRRI Dhan-56 showed the less decrease of chlorophyll content under drought stress that means the reduction rate of photosynthesis is low.
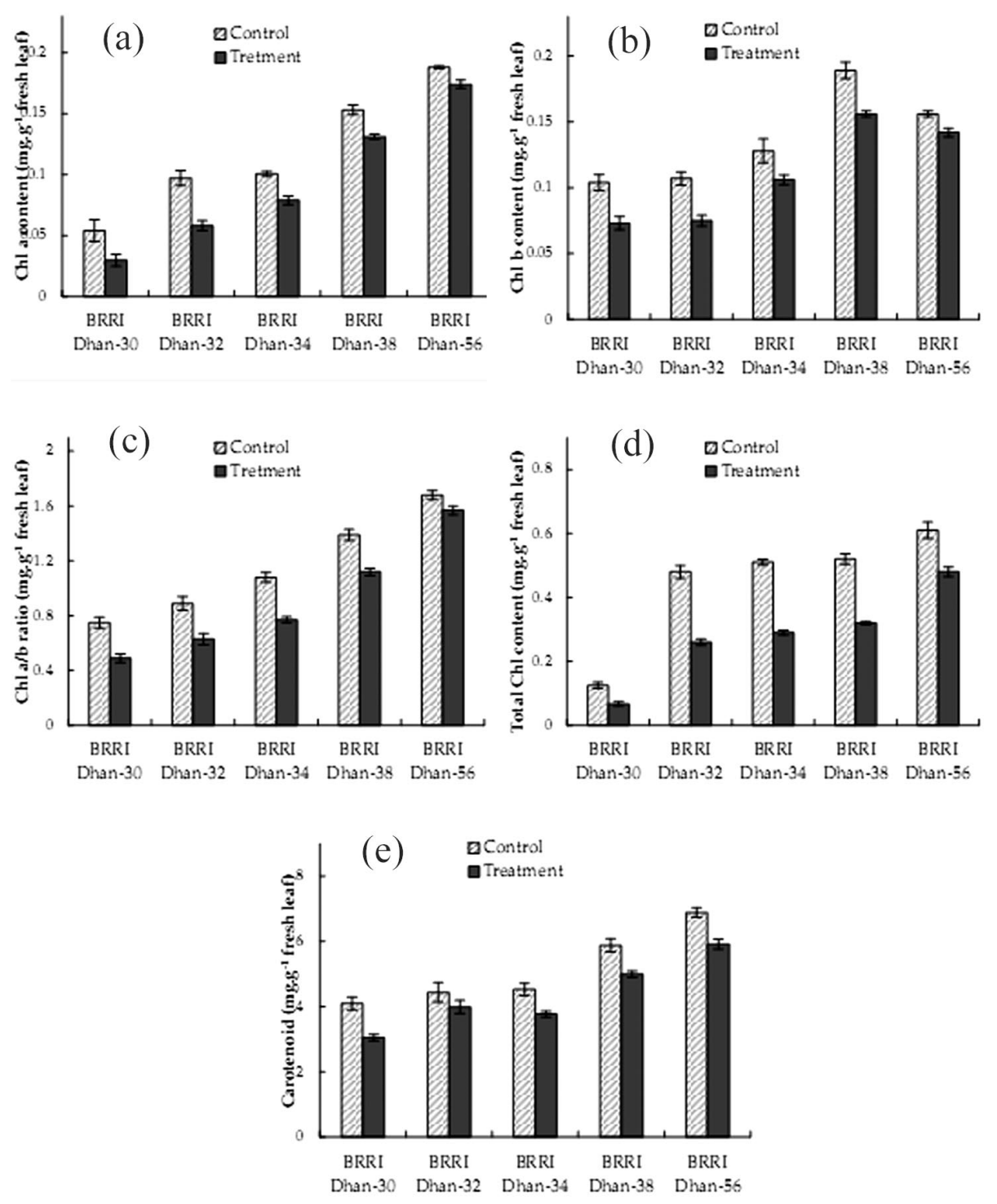

Fig. 1. (a) The effect of drought stress on chlorophyll a content of leaf of rice. Strip sign represent control and solid symbols represent treatment. Each value is the mean of five replicates; the bars represent \pm standard error. (b) The effect of drought stress on chlorophyll b content of leaf of rice. (c) The effect of drought stress on total chlorophyll content of leaf of rice. (d) The effect of drought stress on chlorophyll a/b ratio of leaf of rice. (e) The effect of drought stress on carotenoid contents of leaf of rice. 
Drought stress decreased protein content in the leaf of BRRI Dhan-30, BRRI Dhan-32, BRRI Dhan-34, BRRI Dhan-38 and BRRI Dhan-56 by 41.01, 34.29, 28.89, 25.71 and 3.64\%, respectively, at 15 days of treatment. Among five rice varieties, BRRI Dhan-56 showed the least decrease of protein content under stress (Fig. 2). Similarly, drought stress decreased protein content in rice plant as reported by Choudhary et al. (2009). The reduction of protein content in leaves may cause due to inhibition of protein synthesis or to induce protein denaturation. This result suggests that less reduction of protein content is related to the tolerance of plants under stress.

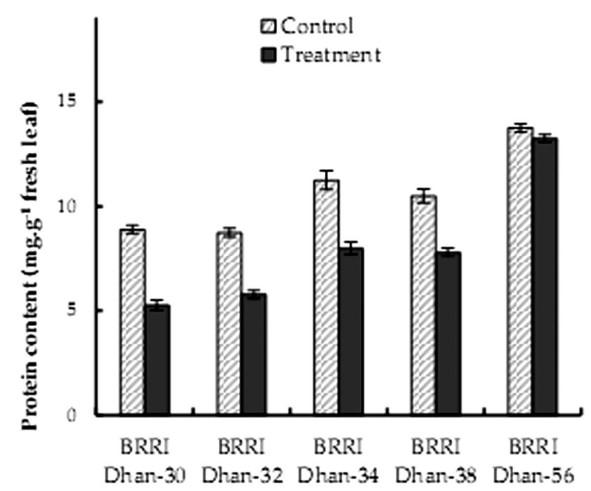

Fig. 2. The effect of drought stress on the accumulation of protein content in the leaf of rice. Strip sign represents control and solid symbols represent treatment. Each value is the mean of five replicates; the bars represent \pm standard error.

Drought stress increased catalase activity in the leaf of BRRI Dhan-30, BRRI Dhan-32, BRRI Dhan-34, BRRI Dhan-38 and BRRI Dhan-56 by 7.65, 13, 15.5, 22.59 and $37.67 \%$, respectively, at 15 days of treatment whereas BRRI Dhan-56 showed the highest increase of CAT activity under stress (Fig. 3a). CAT activity was increased in the drought tolerant varieties of rice (Oryza sativa L.) shown by Fen et al. (2015). It increased Superoxide Dismutase activity in the leaf of BRRI Dhan-30, BRRI Dhan-32, BRRI Dhan-34, BRRI Dhan-38 and BRRI Dhan-56 by 15.38, 24.26, $68.12,70.59$ and $94.17 \%$, respectively, at 15 days of treatment whereas BRRI Dhan-56 showed the highest increase of SOD (94.17\%) activity under stress (Fig. 3b).
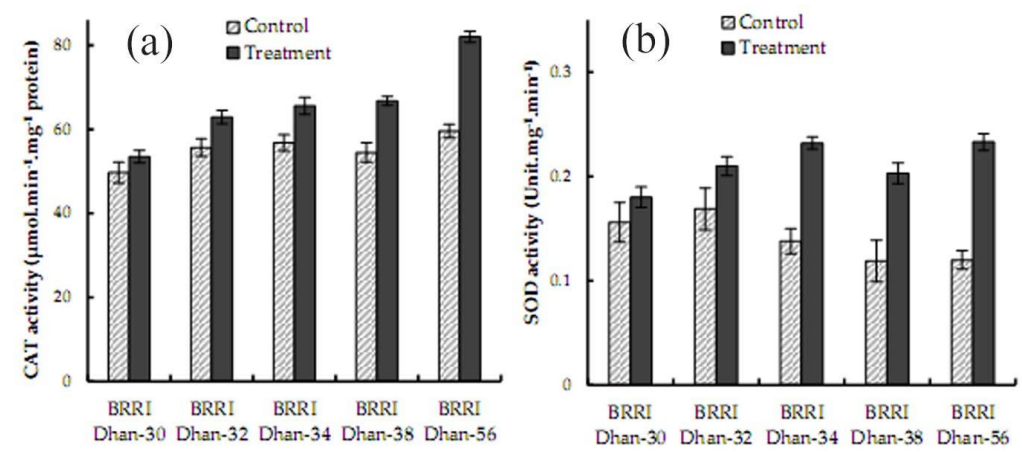

Fig. 3. (a) The effect of drought stress on catalase activity in the leaf of rice. Strip sign represents control and solid symbols represent treatment. Each value is the mean of five replicates; the bars represent \pm standard error. (b) The effect of drought stress on superoxide dismutase activity in the leaf of rice. 
Similar results reported by Lum et al. (2014) that SOD activity enhanced in seedlings exposed to drought stress from the experiment of upland rice varieties (Oryza sativa L.). The balance between ROS production and activities of antioxidative enzyme determines whether oxidative signaling and/or damage will occur (Moller et al. 2007).

Higher antioxidant enzymes activities are related to the tolerance of plants under environmental stresses. For example, the drought-tolerant species of pigeon pea (Cajanus cajan) (Kumar et al. 2011), wheat (Triticum aestivum) (Hasheminasab et al. 2012 and Omar 2012) and black gram (Phaseolus mungo) (Pratap and Sharma 2010) had higher activities of CAT and SOD than the drought-sensitive species.

The present study indicated that BRRI Dhan-56 may be drought tolerant while BRRI Dhan30, BRRI Dhan-32, BRRI Dhan-34 and BRRI Dhan-38 were drought sensitive rice variety. Drought tolerant rice variety (BRRI Dhan-56) is selected based on pigment content, protein content and antioxidant enzymes activities (CAT and SOD).

\section{References}

Akram HM, Ali A, Sattar A, Rehman HSU and Bibi A 2013. Impact of water deficit stress on various physiological and agronomic traits of three Basmati rice (Oryza sativa L.) cultivars. J. Anim. Plant Sci. 23: $1415-1423$.

Akram NA, Waseem M, Ameen R and Ashraf M 2016. Trehalose pre-treatment induces drought tolerance in radish (Raphanus sativus L.) plants: Some key physio-biochemical traits. Acta Physiol. Plant. 38: 3.

Choudhary MK, D Basu, A Datt, N Chakraborty and S Chakraborty 2009. Dehydration responsive nuclear proteome of rice (Oryza sativa L.) illustrates protein network, novel regulation of cellular adaptation and evolutionary perspective. Mol. Cell. Proteomics. 8: 1579-1589.

Fen LL, Ismail MR, Zulkarami B, Rahman MSA and Islam MR 2015. Physiological and molecular characterization of drought responses and screening of drought tolerant rice varieties. Biosci. J. 31(3): 709-718.

Foyer C and Noctor G 2003. Redox sensing and signaling associated with reactive oxygen in chloroplasts, peroxisomes and mitochondria. Physiol. Plant. 119: 355-364.

Habiba U, Shaw R and Takeuchi Y 2012. Farmer's perception and adaptation practices to cope with drought: Perspectives from Northwestern Bangladesh. Int. J. Disaster Risk Reduct. 1:72-84.

Hasheminasab H, Assad MT, Aliakbari A and Sahhafi R 2012. Influence of drought stress on oxidative damage and antioxidant defense systems in tolerant and susceptible wheat genotypes. J. Agric. Sci. 4: 20-30.

Hiscox JD and Israelstam GF 1979. A method for the extraction of chlorophyll from leaf tissue without maceration. Can. J. Bot. 57: 1332-1334.

Kaur G, Kumar S, Nayyar H and Upadhyaya HD 2008. Cold stress injury during the pod-filling phase in chickpea (Cicer arietinum L.): Effects on quantitative and qualitative components of seeds. J. Agron. Crop Sci. 194: 457-464.

Kumar RR, Karajol K and Naik GR 2011. Effect of polyethylene glycol induced water stress on physiological and biochemical responses in pigeon pea (Cajanus cajan L. Mill sp.). Recent Res. Sci. Tech. 3: 148-152.

Lowry OH, Rosenbrough NJ, Farr AL and Randall RJ 1951. Protein measurement with folin- phenol reagent. J. Biol. Chem. 193: 265-275.

Lum MS, Hanafi MM, Rafii YM and Akmar ASN 2014. Effect of drought stress on growth, proline and antioxidant enzyme activities of upland rice. J. Anim. Plant Sci. 24(5): 1487-1493.

Mackinney GJ 1940. Criteria for purity of chlorophyll preparation. J. Biol. Chem. 132: 91-107.

Maclachlan S and Zalik S 1963. Plastid structure, chlorophyll concentration and free amino acid composition of a chlorophyll mutant of barley. Can. J. Bot. 41: 1053-1060. 
Moller IM, Jensen PE and Hansson A 2007. Oxidative modifications to cellular components in plants. Annu. Rev. Plant Biol. 58: 459-481.

Moran JF, Becana M, Iturbe-Ormaetxe I, Frechilla S, Klucas RV and Aparicio-Tejo P 1994. Drought induces oxidative stress in pea plants. Planta 194: 346-352.

Nasrin S, Saha S, Begum HH and Samad R 2020. Impacts of drought stress on growth, protein, proline, pigment content and antioxidant enzyme activities in rice (Oryza sativa L. Var. BRRI Dhan-24). Dhaka University J. Biol. Sci. Vol. 29(1): 117-123.

Nayyar H and Gupta D 2006. Differential sensitivity of $\mathrm{C}_{3}$ and $\mathrm{C}_{4}$ plants to water deficit stress: Association with oxidative stress and antioxidants. Environ. Expert. Bot. 58: 106-113.

Omar AA 2012. Impact of drought stress on germination and seedling growth parameters of some wheat cultivars. Life Sci. J. 9: 590-598.

Pratap V and Sharma YK 2010. Impact of osmotic stress on seed germination and seedling growth in black gram (Phaseolus mungo). J. Environ. Biol. 31: 721-726.

Roy RN and Misra RV 2002. Economic and environmental impact of improved nitrogen management in Asian rice-farming systems. Proceedings of the 20th session of the International Rice Commission 23-26 pp.

Saha S, Samad R, Rashid P and Karmoker JL 2016. Effects of sulphur deficiency on growth, sugars, proline and chlorophyll content in mungbean (Vigna radiata L. var. BARI MUNG-6). Bangladesh J. Bot. 45: 405-410.

Sairam RK and Srivastava GC 2001. Water stress tolerance of wheat (Triticum aestivum L.): Variations in hydrogen peroxide accumulation and antioxidant activity in tolerant and susceptible genotypes. J. Agron. Crop Sci. 186: 63-70.

Seel WE, Hendry GAF and Lee JA 1992. The combined effect of desiccation and irradiance on mosses from xeric and hydric habitats. J. Expt. Bot. 43: 1023-1030.

Song ZP, Lu BR, Zhung YG and J. K. Chen 2003. Gene flow from cultivated rice to the wild species Oryza rufipogon under experimental field conditions. New Phytol. 157:657-665.

Thakur P, Kumar S, Malik JA, Berger JD and Nayyar H 2010. Cold stress effects on reproductive development in grain crops: An overview. Environ. Expt. Bot. 67: 429-443.

Von Wettstein D 1957. Chlorophyll-Letale und der submikroscopische Formwechsel der Plastiden. Expt. Cell Res. 12: 427-506.

Zhang Y, Lu BBL, Ren BY, Tie YP and Zhang XW 2005. Determination of flavone C-glucosides in antioxidant of bamboo leaves fortified foods by reversed phase high-performance liquid chromatography with ultraviolet diode array detection. J. Chromatogr. A. 1065: 177-85.

Manuscript received on 15 May, 2019; revised on 17 March, 2020) 